\title{
Step synthesis and photocatalytic activity of NiO/graphene nanocomposite under UV and visible light as an effective photocatalyst
}

\author{
Faezeh Soofivand, Masoud Salavati-Niasari* \\ Institute of Nano Science and Nano Technology, University of Kashan, Kashan, P. O. Box. 87317-51167, I. R. \\ Iran \\ * Corresponding author. Tel.: +98 31 55912383; E-mail address: Salavati@kashanu.ac.ir
}

\begin{abstract}
In this work, $\mathrm{Ni}(\mathrm{acac})_{2}$ nanostructure was prepared through sublimation method that is a new method for the synthesis of nanomaterials. The temperature of sublimation is an effective parameter on morphology of products, so the role of this parameter on morphology and size of $\mathrm{Ni}(\operatorname{acac})_{2}$ nanostructures was investigated. The uniform $\mathrm{Ni}(\mathrm{acac})_{2}$ nanostructures were considered as an appropriate precursor for synthesis of nickel oxide nanoparticles (NiO NPs) by thermal decomposition method. Finally, NiO/ graphene nanocomposite $(\mathrm{NiO} / \mathrm{G})$ was successfully synthesized by the pre-graphenization route. The as-prepared products were characterized by various analyses such as: SEM, TEM, EDS, VSM, and XRD. The optical band gaps of the pure NiO and $\mathrm{NiO} /$ graphene nanocomposite were estimated about $3.3 \mathrm{eV}$, so these products were considered as semiconductors that can be used as photocatalyst. Increasing the surface and decreasing the possibility of $\left(\mathrm{e}^{-}-\mathrm{h}^{+}\right)$ recombination of nanocomposite were led to the better photocatalytic performance of NiO/graphene nanocomposite than pure $\mathrm{NiO}$. According to the obtained results, degradation of methyl orange (MO) in the presence of $\mathrm{NiO} /$ graphene nanocomposite under $\mathrm{UV}$ and visible light as about $90.3 \%$ after 75 min, and $78 \%$ after 180 min, respectively.
\end{abstract}

Keywords: Nanocomposite; Nanostructures; Photocatalyst; Graphene; Magnetic property; NiO. 


\section{Introduction}

Recently, environmental pollution has become a global crisis; therefore scientists try to present solutions to reduce it. Photocatalysts are one of the most important materials that can decompose pollution through photocatalysis process what is the acceleration of a photoreaction in the presence of a catalyst. Photocatalysis is carried out in two ways; heterogeneous and homogeneous. Heterogeneous photocatalysis is a discipline which includes a large variety of reactions, so they have attracted broad attention due to their properties. Many efforts have been made to find photocatalysts with high yield, the photocatalytic activity depends on the ability of the catalyst to create electron-hole pairs, which generate free radicals (e.g. hydroxyl radicals: $\bullet O H)$ able to undergo secondary reactions. Synthesis of multi-component compounds (example: composite, core-shell and etc.) and preparation of photocatalysts in nano-scale are the solutions to achieve this aim [1-5]. Composite materials are made from two or more materials that are combined together to create a new material with different characteristics in comparison to the individual components. In recent years, composites due to effective applications have become the main field of scientist researches. On the other sides, graphene due to unprecedented properties has become a natural candidate for use in advanced composites. So, researchers interested to study graphene-based nanocomposites and especially graphene-based metal oxide nanocomposites due to various applications [6-8]. Most common heterogeneous photocatalysts are transition metal oxides, which have unique characteristics. They possess avoid energy region (band gap) where no energy levels are available to promote recombination of an electron and hole produced by photo-activation in the solid. Due to the generation of positive holes and negative electrons, oxidation-reduction reactions take place on the surface of semiconductors [9] that cause to decomposition pollutants, finally. So, recombination is an undesirable phenomenon that decreases photocatalytic activity, because of the electrons and holes that are active agents for photocatalytic performance trap. 
Separating the electron-hole is a key parameter in photocatalytic activities, so every agent that helps to delay the recombination process can improve this activity. One of the most important applications of graphene-based metal oxide nanocomposites is photocatalytic activity. Charge transfer between the interfaces of graphene and metal oxides is due to the specific structure and $\mathrm{sp}^{2}$ hybridization of graphene, so recombination process in metal oxide/graphene nanocomposites reduces and photocatalytic activity improves. Hence, graphene-based metal oxides nanocomposites can be used as effective photocatalysts. On the other hand, synthesis of magnetic photocatalysts has recently developed because of the magnetic photocatalysts can be recovered simply through magnetic fields [10].

Nickel oxide is a semiconductor with the formula $\mathrm{NiO}$ that is classified as a basic metal oxide and it is mainly as an intermediate in the production of alloy nickel [11]. NiO has a variety of specialized applications such as anodes for lithium ion batteries [12], cathode materials of alkaline batteries [13], solar cells [14], in chemical (gas) sensing [15], active layer of gas sensors [16] and electrochromic coatings [17], electrochemical supercapacitors [18]. Many efficient techniques were developed for preparation of NiO nanostructures, mainly including sol-gel [19], precipitation [20], sonochemical [21] thermal decomposition [1, 22], microwave [23], water-in-oil microemulsions [24] and so on.

Recently, the sublimation method as a novel route has been developed to synthesize organometallic compounds in nano-scale that are used as precursors for synthesis of metal oxide compounds by thermal decomposition [10, 25-27]. This process is simple and eco-friendly due to its properties such as lowtemperature of the reaction and free-solvent, as well as, using precursor in nano-scale is an advantage of it.

In this work, nickel oxide nanostructures were synthesized via solid-state thermal decomposition of $\mathrm{Ni}(\mathrm{acac})_{2}$ nanostructure as precursor that was prepared by sublimation method. Furthermore, NiO/graphene nanocomposite was prepared by the pre-graphenization method that provides a large amount of sites for loading of NiO. Besides, photocatalytic activity of the synthesized NiO/graphene nanocomposite was studied by 
degradation of methyl orange (MO) as a pollutant. The results of photocatalytic experiments showed that the degradation percentages of MO in existence of the as-prepared nanocomposite under UV and visible light irradiation were about $90.3 \%$ after $75 \mathrm{~min}$, and $78 \%$ after $180 \mathrm{~min}$, respectively, so this product can be used as an effective photocatalyst.

\section{Experimental}

\subsection{Preparation of $\mathrm{Ni}(\mathrm{acac})_{2}$ nanostructures}

$\mathrm{Ni}(\mathrm{acac})_{2}$ nanostructure was prepared by sublimation method, this process was done similar to what was reported in previous works $[10,25-27]$. The range of sublimation temperature in this work was $140-160{ }^{\circ} \mathrm{C}$. The synthesis pathway is shown in Fig. 1. The magnetic properties of the samples were detected at room temperature using a vibrating sample magnetometer (VSM, Meghnatis Kavir Kashan Co., Kashan, Iran). The

small and nail-like depositions were collected and characterized by Scanning electron microscope (SEM), Fourier transform infrared (FT-IR), Transition electron microscope (TEM) and X-ray diffraction (XRD) pattern.

\subsection{Preparation of $\mathrm{NiO}$ nanoparticles}

In this synthesis, $\mathrm{NiO}$ nanoparticles were synthesized by the thermal decomposition of $\mathrm{Ni}(\mathrm{acac})_{2}$ nanostructures as a precursor that was prepared via sublimation method. $0.1 \mathrm{~g}$ of the precursor was placed in a crucible and was heated up to $500{ }^{\circ} \mathrm{C}$ for $120 \mathrm{~min}$. Then, the precipitation was cooled to room temperature and the final product was characterized by XRD, SEM, TEM, EDS (Energy dispersive X-ray spectroscopy) and magnetic properties of the product was investigated by Vibrating sample magnetometer (VSM).

\subsection{Synthesis of GNS from GO}

In this work, the used GO was prepared by a modified Hummers method from natural graphite [28] and reduced through the described method in previous work [29].

\subsection{Preparation of $\mathrm{NiO} /$ graphene nanocomposite}


The NiO/graphene nanocomposite was synthesized via a pre-graphenization technique. Briefly, $0.1 \mathrm{~g}$ from obtained $\mathrm{NiO}$ nanoparticles $(0.4 \mathrm{mmol})$ was added to the black suspension of graphene $\left(0.5 \mathrm{mg} \mathrm{mL}^{-1}\right)$ and magnetically stirred for $20 \mathrm{~min}$ at $90{ }^{\circ} \mathrm{C}$. Finally, the above mixture was put in a household microwave oven (Haier, $2450 \mathrm{MHz}, 750 \mathrm{~W}$ ) for $10 \mathrm{~min}$ and then it was cooled to room temperature, naturally. Subsequently, the black precipitation was filtered, washed with distilled water and absolute alcohol, and dried at $100{ }^{\mathrm{O}} \mathrm{C}$ for $12 \mathrm{~h}$ in a vacuum oven. The resulted black powder was collected for the following characterization. The product was characterized by XRD, SEM and UV-vis spectroscopy.

\subsection{Characterization}

The crystalline phase of the precursor and products were analyzed using a diffractometer of the Philips Company with X'PertPro monochromatized $\mathrm{Cu} \mathrm{K \alpha}$ radiation $(\lambda=1.54 \AA$ A). Fourier transform infrared (FT-IR) spectra were recorded on Shimadzu Varian 4300 spectrophotometer in KBr pellets. Microscopic morphology of the products was studied by FESEM (Mira3 tescan) and TEM (HT-7700). The energy dispersive spectrometry (EDS) analysis was studied by XL30, Philips microscope. Magnetic properties were measured using a vibrating sample magnetometer (VSM) (Meghnatis Kavir Kashan Co., Kashan, Iran). The source of UV and visible light were OSRAM HTC 400W $(\lambda=315-400 \mathrm{~nm})$ and a $300 \mathrm{~W}$ xenon lamp with a $420 \mathrm{~nm}$ cut-off filter $(\lambda>420$ $\mathrm{nm})$, respectively.

\section{Results and Discussions}

\subsection{SEM images of of $\mathrm{Ni}(\text { acac })_{2}$}

The effect of sublimation temperature on morphology of $\mathrm{Ni}(\mathrm{acac})_{2}$ was investigated. The SEM images of the sublimated $\mathrm{Ni}(\mathrm{acac})_{2}$ at $140{ }^{\circ} \mathrm{C}$ (sample no. 1), $150{ }^{\circ} \mathrm{C}$ (sample no. 2), and $160{ }^{\circ} \mathrm{C}$ (sample no. 3) are shown in Fig. 2 (a-c), respectively. In Fig. 2a, are shown one-dimensional (1-D) structures with diameter about $30 \mathrm{~nm}$. Fig. 2b illustrates the (1-D) structures with diameters about $100 \mathrm{~nm}$ along with unknown structures. The agglomerated and large particles with size about $200 \mathrm{~nm}$ obtained at $160{ }^{\mathrm{O}} \mathrm{C}$ (Fig. 2c). By considering SEM 
images, sample 1 was chosen as the precursor obtained in optimum condition because of the homogeneity of 1$\mathrm{D}$ structures is highest and diameter of them is the lowest. $\mathrm{NiO}$ nanoparticles were synthesized by thermal decomposition of $\mathrm{Ni}(\mathrm{acac})_{2}$ nanostructures at $500{ }^{\circ} \mathrm{C}$ for $120 \mathrm{~min}$ (sample no. 4),

In order to the observation of morphology and size of the sample no. 1, the TEM image of sample no. 1 was recorded and was given in Fig. 2d. This image indicates that as-prepared $\mathrm{Ni}(\mathrm{acac})_{2}$ nanostructures consist of nano-scale fibers with an average size of diameter and length about 10 and $50 \mathrm{~nm}$, respectively.

\subsection{XRD pattern and FT-IR spectrum of $\mathrm{Ni}(\text { acac })_{2}$}

Fig. 3 shows the XRD pattern of sample no.1. All of the reflection peaks in this pattern can be attributed to nickel acetylacetonate dihydrate with the unknown structure and without miller indices (JCPDS card No. 441565). $\mathrm{Ni}(\mathrm{acac})_{2} .2 \mathrm{H}_{2} \mathrm{O}$ can be transformed to anhydrous $\mathrm{Ni}(\mathrm{acac})_{2}$ by subliming at $170-210{ }^{\circ} \mathrm{C}$ [30]. So, sample 1 was sublimed at $170{ }^{\circ} \mathrm{C}$, again for obtaining anhydrous Ni(acac) $)_{2}$. The XRD pattern of sample no.1 after again sublimation at $170{ }^{\circ} \mathrm{C}$ is shown in Fig. 4a. All of the reflection peaks in this pattern can be attributed to nickel acetylacetonate with the orthorhombic structure (JCPDS card No. 10-0735; a $=15.56, \mathrm{~b}=23.23, \mathrm{c}=$ $\left.9.64^{\circ} \mathrm{A}\right)$. No other peak exists in Fig. $4 \mathrm{a}$, confirming the high purity of the sample. The average crystallite diameter of anhydrous $\mathrm{Ni}(\mathrm{acac})_{2}$ was calculated about $21 \mathrm{~nm}$ by the Scherrer equation [31].

FT-IR spectrum of sample no. 1 after again sublimation is shown in Fig. 4b. This spectrum shows an absorption band at $460 \mathrm{~cm}^{-1}$, which may be assigned to the $\mathrm{Ni}-\mathrm{O}$ vibration mode. The important peak at 1554 $\mathrm{cm}^{-1}$ in the spectrum, correspond to mode stretching $\mathrm{C}=\mathrm{O}$ and the shifting of carbonyl group peak is due to the interaction of the metal with oxygen and resonance in ligand that this resonance is confirmed by the $\mathrm{C}-\mathrm{O}$ weak peak at $1283 \mathrm{~cm}^{-1}$. The weak peak at $2942 \mathrm{~cm}^{-1}$ corresponding to methyl and methylene groups asymmetric stretching vibrations. The broad absorption band around $3450 \mathrm{~cm}^{-1}$ is corresponding to the $\mathrm{v}(\mathrm{O}-\mathrm{H})$ stretching vibrations of water molecules adsorbed on the surface of $\mathrm{Ni}(\mathrm{acac})_{2}$ nanostructures.

\subsection{SEM and TEM images of $\mathrm{NiO}$}


The SEM image of the as-synthesized $\mathrm{NiO}$ (sample no. 4) is shown in Fig. 5a. In this image, are shown the particles with size about $50 \mathrm{~nm}$. The TEM and Selected area electron diffraction (SAED) images of the NiO nanoparticles (sample no. 4) are illustrated in Fig. 5b and c, respectively. Uniform NiO nanoparticles with size about $20 \mathrm{~nm}$ can be seen in Fig. 5b. The SEAD pattern indicates that the NiO nanoparticles are polycrystalline. They are further indexed as the cubic phase (Fig. 5c). The HRTEM image of the NiO nanoparticles is shown in Fig. 5d. The interplanar spacing is about $0.24 \mathrm{~nm}$, which corresponds to the $\left(\begin{array}{lll}1 & 1 & 1\end{array}\right)$ plane of the cubic crystalline NiO. Therefore, the HRTEM image further verifies the cubic nature of the synthesized NiO nanoparticles.

\subsection{XRD pattern and EDS spectrum of $\mathrm{NiO}$}

XRD pattern of $\mathrm{NiO}$ nanoparticles (sample no. 4) is shown in Fig. 6a. It is indexed as a pure cubic structure with according to the literature value (JCPDS card no. 78-0429, Space group: Fm-3m, $a=b=c=4.1771$ ). The crystallite size was estimated using the Scherrer equation is about $30 \mathrm{~nm}$ [31]. Fig. 6b shows the EDS microanalysis of the obtained $\mathrm{NiO}$ nanoparticles. The $\mathrm{Ni}$ and $\mathrm{O}$ elements in this spectrum were characterized and there were no peaks, so, the purity of the synthesized $\mathrm{NiO}$ nanoparticles was confirmed.

\subsection{SEM image and XRD pattern of $\mathrm{NiO} /$ graphene nanocomposite}

Fig. 7a and $\mathrm{b}$ show the low and high magnification FESEM images of the NiO/graphene nanocomposite. From the high magnification image (Fig. 7b), it is clear that the product consists sheet-like structures that $\mathrm{NiO}$ nanoparticles $(20-30 \mathrm{~nm})$ put on them.

The purity of the NiO/graphene nanocomposite was confirmed by X-ray diffraction (XRD) pattern. The diffraction peaks $\left(\begin{array}{lll}1 & 1 & 1\end{array}\right),\left(\begin{array}{lll}2 & 0 & 0\end{array}\right),\left(\begin{array}{lll}2 & 2 & 0\end{array}\right)$, and $\left(\begin{array}{lll}3 & 1 & 1\end{array}\right)$ in Fig. 7c can be indexed to the cubic phase NiO with space group of Fm/ 3m (JCPDS No. 78-0429) and the broad peak located at 26.5 (l $\left.\begin{array}{lll}0 & 0\end{array}\right)$ corresponds to layered GNS [32]. Presence of NiO crystals in the graphene-based composite was confirmed by the other diffraction peaks in this pattern (Fig. 7c), this result was supported by SEM image (Fig. 6a, b).

\subsection{VSM analyses}


Magnetization curves of $\mathrm{NiO}$ nanoparticles (sample no. 4) and $\mathrm{NiO} /$ graphene nanocomposite at room temperature are shown in Fig. 8a and b, respectively. $\mathrm{NiO}$ nanoparticles and $\mathrm{NiO}$ /graphene nanocomposite depict a pseudo-single domain and superparamagnetic behavior, respectively, although bulk NiO has now been antiferromagnetic [33]. Pseudo-single domain behavior of $\mathrm{NiO}$ and superparamagnetism characteristic of $\mathrm{NiO} /$ graphene nanocomposite is confirmed by two signs: The ' $\mathrm{S}$ '-shaped curve and low coercivity $(\mathrm{Hc}=214.2$ Oe for $\mathrm{NiO}$ nanoparticles) [34], the saturation magnetization, $\mathrm{Ms}=1 \mathrm{emu} / \mathrm{g}$ is reached at an applied field of 6000 Oe.

Superparamagnetism occurs in nanoparticles, which are single-domain, i.e. composed of a single magnetic domain and this is possible when their diameter is below $50 \mathrm{~nm}$, depending on the materials. When an external magnetic field is applied to an assembly of superparamagnetic nanoparticles, their magnetic moments tend to align along the applied field, leading to a net magnetization. The magnetization curve of the assembly, i.e. the magnetization as a function of the applied field, is a reversible S-shaped increasing function [35]. This change in magnetic property of bulk and $\mathrm{NiO}$ nanoparticles and $\mathrm{NiO} /$ graphene nanocomposite can be ascribed to finite size effect and unique structure of graphene. With decreasing size of magnetic particles: 1) finite size effect becomes more important and 2) the presence of defects, lattice expansion, broken nature of exchange bonds, and fluctuations in the number of atomic neighbors cause disorder of surface spin and frustration [36].

Recently, extensive studies have been reported about particle size dependent magnetic properties [37-39] and finite size versus surface effects [40] on magnetic properties of $\mathrm{NiO}$ systems have been studied and these investigations show that the strong interplay between finite size effects, surface and interface effects, and defects or oxygen vacancies cause the magnetic properties in $\mathrm{NiO}$ become very complex [36].

\subsection{UV-vis absorption spectra}

Fig. 9a, and b show the UV-vis absorption spectra of the NiO nanoparticles (sample no. 4) and NiO/graphene nanocomposite, respectively. In these spectra, an absorption peak around approximate 360 nm can be observed, 
which is similar to Salavati-Niasari' report and the strong absorption in the UV region is attributed to direct excitation of the $\mathrm{NiO}$ [41]. Increasing of the absorption intensity in the UV and visible regions is due to the presence of graphene sheets in the composite. The enhanced absorption can be attributed to the reduced graphene as in accordance with the UV-vis spectrum of plain graphene (Fig. 9c).

Optical band gap (Eg) may be evaluated based on the optical absorption spectrum using the following equation [42]: (Ahv) ${ }^{\mathrm{n}}=\mathrm{B}(\mathrm{hv}-\mathrm{Eg})$; Where hv is the photon energy, $\mathrm{A}$ is absorbent, B is a material constant and $\mathrm{n}$ is 2 or $1 / 2$ for direct and indirect transitions, respectively. The optical band gap for the absorption peak is obtained by extrapolating the linear portion of the $(\mathrm{Ahv})^{\mathrm{n}}$ curve versus ho to zero. No linear relation was found for $\mathrm{n}=1 / 2$, suggesting that the prepared $\mathrm{NiO}$ nanoparticles are semiconductors with a direct transition at this energy. The band gap of as-prepared $\mathrm{NiO} /$ graphene nanocomposite was calculated about $3.3 \mathrm{eV}$ (Fig. 9d) which is similar to the values reported by other researchers [41, 43]. It has a red-shift to that of bulk NiO (3.5 eV) [44] which could be ascribed to the interaction of $\mathrm{NiO}$ with graphene backbone [45] and large surface of $\mathrm{NiO}$ graphene nanocomposite.

\subsection{Photocatalytic activity and its mechanism}

The photocatalytic activities of $\mathrm{NiO} /$ graphene nanocomposite and pure $\mathrm{NiO}$ nanoparticles synthesized in this work (see experimental section) were investigated by monitoring the degradation of methyl orange solution (MO) dye under UV (Fig. 10), and visible (Fig. 11) light irradiation.

The photocatalytic degradation reactions were performed in a quartz photocatalytic reactor and carried out with $0.05 \mathrm{~g}$ of $\mathrm{MO}$ solution containing $0.05 \mathrm{~g}$ of photocatalyst (NiO/graphene nanocomposite or pure $\mathrm{NiO}$ nanoparticles synthesized in this work). This mixture was aerated for 30 min to reach adsorption equilibrium. Then, the mixture was placed inside the photoreactor in which the vessel was $40 \mathrm{~cm}$ away from the UV and visible source. The quartz vessel and light sources were placed inside a black box equipped with a fan to 
prevent UV leakage. The experiments were performed at room temperature and $\mathrm{pH}$ of the $\mathrm{MO}$ solution was adjusted 2-3. The MO degradation percentage was calculated by Eq. (1) as follows:

D.P. $(\mathrm{t})=\left(\mathrm{A}_{0}-\mathrm{A}_{\mathrm{t}}\right) /\left(\mathrm{A}_{0} \times 100\right)$

where $A_{0}$ and $A_{t}$ are absorbance value of the MO solution at 0 and $t$ min, respectively [46]. According to photocatalytic calculations by Eq. (1), the MO degradation under UV irradiation in the presence of $\mathrm{NiO} /$ graphene nanocomposite and pure $\mathrm{NiO}$ nanoparticles were about $90.3 \%$ and $74.4 \%$ after $75 \mathrm{~min}$, respectively (Fig. 10).

The photocatalytic activities of $\mathrm{NiO} /$ graphene nanocomposite and pure $\mathrm{NiO}$ nanoparticles under visible light irradiation were evaluated by the degradation of MO. Fig. 11 illustrates the degradation efficiency of desired dye (MO) on the as- photocatalysts synthesized as a function of reaction time. The percentages of degradation in the presence of $\mathrm{NiO} /$ graphene nanocomposite and pure $\mathrm{NiO}$ nanoparticles under visible source obtained about $78 \%$ and $60.5 \%$, after $180 \mathrm{~min}$, respectively. As shown, the photocatalytic activities of NiO/graphene nanocomposite under UV and visible irradiation are more than pure NiO nanoparticles. The photocatalytic degradation of $\mathrm{MO}$ with $\mathrm{NiO} /$ graphene nanocomposite was explained by the photogeneration of electron-hole pairs between the conduction (CB) and valence bands (VB) due to excitation of NiO under UV light illumination [47]. Also, by considering previous works, the supported photocatalysts (such as graphene-based nanocomposites) have a high tendency for trapping or absorbance of reactants and that facilitated transfer of reactants to active sites $[10,48]$.

In this work, the superior photocatalytic activity may be related to the high surface area, the high separation rate of charge carriers, excellent structure, and great electrical and optical properties of graphene layers of nanocomposite.

The two mechanisms for photocatalytic activities of pure $\mathrm{NiO}$ and $\mathrm{NiO} /$ graphene nanocomposite were proposed as follows: 
The proposed photocatalytic mechanism for pure $\mathrm{NiO}$ nanoparticles:

$$
\begin{aligned}
& \mathrm{UV}+\mathrm{NiO} \longrightarrow \mathrm{NiO}^{\circ}\left(\mathrm{h}^{+}+\mathrm{e}\right) \\
& \mathrm{h}^{*}+\mathrm{H}_{2} \mathrm{O} \longrightarrow \mathrm{H}^{*}+{ }^{\circ} \mathrm{OH} \\
& 2 \mathrm{~h}^{+}+2 \mathrm{H}_{2} \mathrm{O} \longrightarrow 2 \mathrm{H}^{+}+\mathrm{H}_{2} \mathrm{O}_{2} \\
& \mathrm{H}_{2} \mathrm{O}_{2} \longrightarrow{ }^{\circ} \mathrm{OH}+{ }^{\circ} \mathrm{OH} \\
& \mathrm{e}^{\circ}+\mathrm{O}_{2} \longrightarrow{ }^{\circ} \mathrm{O}_{2}^{-} \\
& { }^{\circ} \mathrm{O}_{2}+2 \mathrm{OH}^{\circ}+\mathrm{H}^{+} \longrightarrow \mathrm{H}_{2} \mathrm{O}_{2}+\mathrm{O}_{2} \\
& \mathrm{H}_{2} \mathrm{O}_{2} \longrightarrow{ }^{\circ} \mathrm{OH}+{ }^{\circ} \mathrm{OH} \\
& { }^{\circ} \mathrm{OH}+\text { dye } \longrightarrow \text { degradation of dye }
\end{aligned}
$$

The proposed photocatalytic mechanism for $\mathrm{NiO} /$ graphene nanocomposite:

$$
\begin{aligned}
& \mathrm{NiO}+\mathrm{hv} \longrightarrow\left(\mathrm{e}_{\mathrm{CB}}^{-}\right)+\left(\mathrm{h}_{\mathrm{vB}}^{+}\right) \longrightarrow \text { graphene }\left(\mathrm{e}^{-}+\mathrm{h}^{+}\right) \\
& \mathrm{NiO}\left(\mathrm{e}_{\mathrm{CB}}\right)+\mathrm{O}_{2, \text { ads }} \longrightarrow{ }^{\circ} \mathrm{O}_{2}+\mathrm{NiO} \stackrel{\mathrm{H}_{2} \mathrm{O}}{\longrightarrow}{ }^{\circ} \mathrm{OH}+\mathrm{NiO} \\
& \mathrm{NiO}\left(\mathrm{h}_{\mathrm{vB}}^{+}\right)+\mathrm{OH}_{\text {ads }} \longrightarrow{ }^{\circ} \mathrm{OH}+\mathrm{NiO} \\
& \text { graphene }(\mathrm{e})+\mathrm{O}_{2, \text { ads }} \longrightarrow{ }^{\circ} \mathrm{O}_{2}+\text { graphene } \stackrel{\mathrm{H}}{2} \mathrm{O}^{\circ} \mathrm{OH}+\text { graphene }
\end{aligned}
$$

\section{dye $+{ }^{\circ} \mathrm{OH} \longrightarrow$ Degradation of dye}

According to these mechanisms, it can be said that graphene layers can postpone the recombination process, so the performance of nanocomposite is better than pure $\mathrm{NiO}$ nanoparticles. Furthermore, high surface area, the high separation rate of charge carriers, excellent structure, and great electrical and optical properties of graphene layers of nanocomposite can increase the photocatalytic yield of the graphene-based nanocomposite.

\section{Conclusions}

In summary, here sublimation method was presented as a novel vapor-deposition method for purification and preparation of (1-D) one-dimensional $\mathrm{Ni}(\mathrm{acac})_{2}$ nanostructures. Sublimation method is a green, low-cost, simple, convenient and effective solid-state technique for preparation of nanomaterials. To investigate the effect of sublimation temperature on morphology of $\mathrm{Ni}(\mathrm{acac})_{2}, \mathrm{Ni}(\mathrm{acac})_{2}$ powder was sublimated in various 
temperatures and the as-prepared sample with the optimal morphology was chosen as a precursor for synthesis of $\mathrm{NiO}$ nanoparticles. The results show that increasing the sublimation temperature increases the size of structures, so $\mathrm{T}=140{ }^{\mathrm{O}} \mathrm{C}$ was chosen as the optimum temperature for preparation of precursor in nano-scale. $\mathrm{NiO}$ nanoparticles were produced by thermal decomposition of $\mathrm{Ni}(\mathrm{acac})_{2}$ sublimated at $140{ }^{\mathrm{O}} \mathrm{C}$. At the next step, $\mathrm{NiO} /$ graphene nanocomposite was prepared through pre-graphenization and $\mathrm{NiO}$ nanoparticles were anchored onto graphene sheets. VSM analyses depict that $\mathrm{NiO}$ nanoparticles and $\mathrm{NiO} /$ graphene nanocomposite present a pseudo-single domain and superparamagnetic behavior, respectively. The preparation of $\mathrm{NiO}$ /graphene nanocomposite can help to delay the recombination process, so the photocatalytic performance improves. According to the results obtained from photooxidation of methyl orange (MO), it was found that degradation percentages of MO were about 90.3 and 78 under UV and visible irradiation, respectively. Hence, $\mathrm{NiO} /$ graphene nanocomposite was identified as an effective adsorbent and photocatalyst in waste-water treatment because of it shows an excellent performance to remove pollutants, rapidly.

\section{Acknowledgements}

Authors are grateful to the council of Iran National Science Foundation and University of Kashan for supporting this work by Grant No (159271/779). 


\section{References}

[1] F. Motahari, M.R. Mozdianfard, F. Soofivand, M. Salavati-Niasari, NiO nanostructures: synthesis, characterization and photocatalyst application in dye wastewater treatment, RSC Advances, 4 (2014) 2765427660.

[2] A. Sharma, B.-K. Lee, Adsorptive/photo-catalytic process for naphthalene removal from aqueous media using in-situ nickel doped titanium nanocomposite, Journal of environmental management, 155 (2015) 114-122.

[3] A. Sharma, B.-K. Lee, Integrated ternary nanocomposite of $\mathrm{TiO} 2 / \mathrm{NiO} /$ reduced graphene oxide as a visible light photocatalyst for efficient degradation of o-chlorophenol, Journal of Environmental Management, 181 (2016) 563-573.

[4] A. Sharma, B.-K. Lee, Structure and activity of $\mathrm{TiO} 2 / \mathrm{FeO}$ co-doped carbon spheres for adsorptivephotocatalytic performance of complete toluene removal from aquatic environment, Applied Catalysis A: General, 523 (2016) 272-282.

[5] F. Soofivand, M. Salavati-Niasari, Co 3 O 4/graphene nanocomposite: pre-graphenization synthesis and photocatalytic investigation of various magnetic nanostructures, RSC Advances, 5 (2015) 64346-64353.

[6] J. Liu, H. Cao, J. Xiong, Z. Cheng, Ferromagnetic hematite@ graphene nanocomposites for removal of rhodamine B dye molecules from water, CrystEngComm, 14 (2012) 5140-5144.

[7] H. Zhang, X. Lv, Y. Li, Y. Wang, J. Li, ACS NANO, 4 (2010) 380.

[8] L. Jiang, M. Yao, B. Liu, Q. Li , R. Liu, H. Lv, S. Lu, C. Gong, B. Zou, T. Cui, B. Liu, J. Phys. Chem., C 116 (2012) 11741.

[9] A.L. Linsebigler, G. Lu, J.T. Yates Jr, Photocatalysis on TiO2 surfaces: principles, mechanisms, and selected results, Chemical reviews, 95 (1995) 735-758.

[10] F. Soofivand, M. Salavati-Niasari, RSC Adv., 5 (2015) 64346-64353. 
[11] K. Lascelles, L. Morgan, D. Nicholls, D. Beyersmann, Nickel compounds, Ullmann's Encyclopedia of Industrial Chemistry, in, Wiley-VCH Verlag GmbH \& Co. KGaA, 2005.

[12] H.K. Liu, G. Wang, Z.P. Guo, J.Z. Wang, K. Konstantinov, The impact of nanomaterials on Li-ion rechargeable batteries, Verified OK, (2007).

[13] J. Bahadur, D. Sen, S. Mazumder, S. Ramanathan, Effect of heat treatment on pore structure in nanocrystalline NiO: A small angle neutron scattering study, Journal of Solid State Chemistry, 181 (2008) 12271235.

[14] J. Bandara, H. Weerasinghe, Solid-state dye-sensitized solar cell with p-type $\mathrm{NiO}$ as a hole collector, Solar Energy Materials and Solar Cells, 85 (2005) 385-390.

[15] C.-G. Granqvist, G.A. Niklasson, A. Azens, Electrochromics: Fundamentals and energy-related applications of oxide-based devices, Applied Physics A, 89 (2007) 29-35.

[16] I. Hotovy, J. Huran, L. Spiess, S. Hascik, V. Rehacek, Preparation of nickel oxide thin films for gas sensors applications, Sensors and Actuators B: Chemical, 57 (1999) 147-152.

[17] C.-Y. Lee, C.-M. Chiang, Y.-H. Wang, R.-H. Ma, A self-heating gas sensor with integrated NiO thin-film for formaldehyde detection, Sensors and Actuators B: Chemical, 122 (2007) 503-510.

[18] V. Srinivasan, J.W. Weidner, An electrochemical route for making porous nickel oxide electrochemical capacitors, Journal of the Electrochemical Society, 144 (1997) L210-L213.

[19] A. Šurca, B. Orel, B. Pihlar, P. Bukovec, Optical, spectroelectrochemical and structural properties of solgel derived Ni-oxide electrochromic film, Journal of Electroanalytical Chemistry, 408 (1996) 83-100.

[20] J. Li, R. Yan, B. Xiao, D.T. Liang, D.H. Lee, Preparation of Nano-NiO Particles and Evaluation of Their Catalytic Activity in Pyrolyzing Biomass Componentsł๋, Energy \& Fuels, 22 (2007) 16-23.

[21] S.M. Meybodi, S. Hosseini, M. Rezaee, S. Sadrnezhaad, D. Mohammadyani, Synthesis of wide band gap nanocrystalline $\mathrm{NiO}$ powder via a sonochemical method, Ultrasonics sonochemistry, 19 (2012) 841-845. 
[22] M. El-Kemary, N. Nagy, I. El-Mehasseb, Nickel oxide nanoparticles: Synthesis and spectral studies of interactions with glucose, Materials Science in Semiconductor Processing, 16 (2013) 1747-1752.

[23] X. Song, L. Gao, Facile synthesis of polycrystalline NiO nanorods assisted by microwave heating, Journal of the American Ceramic Society, 91 (2008) 3465-3468.

[24] A. Kumar, A. Saxena, A. De, R. Shankar, S. Mozumdar, Controlled synthesis of size-tunable nickel and nickel oxide nanoparticles using water-in-oil microemulsions, Advances in Natural Sciences: Nanoscience and Nanotechnology, 4 (2013) 025009.

[25] F. Soofivand, M. Salavati-Niasari, Novel solvent-less synthesis of $\mathrm{CuO}$ nanoparticles by using sublimated precursors, Materials Letters, 106 (2013) 83-86.

[26] F. Soofivand, M. Salavati-Niasari, Synthesis and characterization of highly luminescent EuOF nanoceramics by using prepared Eu (FOD) 3 nanoparticles via sublimation method as precursor, Ceramics International, 41 (2015) 14394-14399.

[27] F. Soofivand, M. Salavati-Niasari, F. Mohandes, Novel precursor-assisted synthesis and characterization of zinc oxide nanoparticles/nanofibers, Materials Letters, 98 (2013) 55-58.

[28] W.S. Hummers Jr, R.E. Offeman, Preparation of graphitic oxide, Journal of the American Chemical Society, 80 (1958) 1339-1339.

[29] C.-M. Chen, Q. Zhang, J.-Q. Huang, W. Zhang, X.-C. Zhao, C.-H. Huang, F. Wei, Y.-G. Yang, M.-Z. Wang, D.S. Su, Chemically derived graphene-metal oxide hybrids as electrodes for electrochemical energy storage: pre-graphenization or post-graphenization?, Journal of Materials Chemistry, 22 (2012) 13947-13955. [30] G. Bullen, R.t. Mason, P. Pauling, The crystal and molecular structure of bis (acetylacetonato) nickel (II), Inorganic Chemistry, 4 (1965) 456-462.

[31] A. Sobhani, M. Salavati-Niasari, S.M. Hosseinpour-Mashkani, Single-source molecular precursor for synthesis of copper sulfide nanostructures, Journal of Cluster Science, 23 (2012) 1143-1151. 
[32] W.-C. Oh, F.-J. Zhang, M.-L. Chen, Characterization and photodegradation characteristics of organic dye for Pt-titania combined multi-walled carbon nanotube composite catalysts, Journal of industrial and engineering chemistry, 16 (2010) 321-326.

[33] A. Ngo, P. Bonville, M. Pileni, Nanoparticles of: Synthesis and superparamagnetic properties, The European Physical Journal B-Condensed Matter and Complex Systems, 9 (1999) 583-592.

[34] M.A. Khadar, V. Biju, A. Inoue, Effect of finite size on the magnetization behavior of nanostructured nickel oxide, Materials research bulletin, 38 (2003) 1341-1349.

[35] L. Néel, Théorie du traînage magnétique de diffusion, Journal de Physique et le Radium, 13 (1952) 249264.

[36] B. Kisan, P. Shyni, S. Layek, H. Verma, D. Hesp, V. Dhanak, S. Krishnamurthy, A. Perumal, Finite size effects in magnetic and optical properties of antiferromagnetic $\mathrm{NiO}$ nanoparticles, Magnetics, IEEE Transactions on, 50 (2014) 1-4.

[37] M. Peck, Y. Huh, R. Skomski, R. Zhang, P. Kharel, M. Allison, D. Sellmyer, M. Langell, Magnetic properties of $\mathrm{NiO}$ and (Ni, Zn) O nanoclusters, Journal of Applied Physics, 109 (2011) $07 \mathrm{~B} 518$.

[38] S. Tiwari, K. Rajeev, Signatures of spin-glass freezing in NiO nanoparticles, Physical Review B, 72 (2005) 104433.

[39] L. Li, L. Chen, R. Qihe, G. Li, Magnetic crossover of NiO nanocrystals at room temperature, Applied physics letters, 89 (2006) 134102.

[40] S. Mandal, K.S. Menon, S. Mahatha, S. Banerjee, Finite size versus surface effects on magnetic properties of antiferromagnetic particles, Applied Physics Letters, 99 (2011) 232507.

[41] M. Salavati-Niasari, F. Davar, Z. Fereshteh, Synthesis of nickel and nickel oxide nanoparticles via heattreatment of simple octanoate precursor, Journal of alloys and Compounds, 494 (2010) 410-414. 
[42] A. Hagfeldt, M. Graetzel, Light-induced redox reactions in nanocrystalline systems, Chemical Reviews, 95 (1995) 49-68.

[43] M. Salavati-Niasari, N. Mir, F. Davar, A novel precursor in preparation and characterization of nickel oxide nanoparticles via thermal decomposition approach, Journal of Alloys and Compounds, 493 (2010) 163168.

[44] Y. Xu, M.A. Schoonen, The absolute energy positions of conduction and valence bands of selected semiconducting minerals, American Mineralogist, 85 (2000) 543-556.

[45] Q. Liu, Z. Liu, X. Zhang, L. Yang, N. Zhang, G. Pan, S. Yin, Y. Chen, J. Wei, Polymer photovoltaic cells based on solution-processable graphene and P3HT, Advanced Functional Materials, 19 (2009) 894-904.

[46] F. Soofivand, F. Mohandes, M. Salavati-Niasari, Silver chromate and silver dichromate nanostructures: sonochemical synthesis, characterization, and photocatalytic properties, Materials Research Bulletin, 48 (2013) 2084-2094.

[47] F. Tao, Y. Shen, L. Wang, Controlled fabrication of flower-like nickel oxide hierarchical structures and their application in water treatment, Molecules, 17 (2012) 703-715.

[48] V. Jeyalakshmi, R. Mahalakshmy, K. Krishnamurthy, B. Viswanathan, Titania based catalysts for photoreduction of carbon dioxide: Role of modifiers, Indian Journal of Chemistry-Part A InorganicPhysical Theoretical and Analytical, 51 (2012) 1263. 


\section{Figure captions:}

Fig. 1. The synthesis pathway of sublimation process with dual roles: purification and preparing of nano-size $\mathrm{Ni}(\mathrm{acac})_{2}$.

Fig. 2. SEM images of sublimated $\mathrm{Ni}(\mathrm{acac})_{2}$ at (a) $140{ }^{\mathrm{O}} \mathrm{C}$, (b) $150{ }^{\mathrm{O}} \mathrm{C}$, (c) $160{ }^{\mathrm{O}} \mathrm{C}$ and (d) TEM image of sublimated $\mathrm{Ni}(\text { acac })_{2}$ at $140{ }^{\mathrm{O}} \mathrm{C}$.

Fig. 3. XRD pattern of $\mathrm{Ni}(\text { acac })_{2} .2 \mathrm{H}_{2} \mathrm{O}$ (sample 1).

Fig. 4. (a) XRD pattern and (b) FT-IR spectrum of anhydrous $\mathrm{Ni(acac})_{2}$.

Fig. 5. (a) SEM and (b) TEM, (c) SAED pattern and (d) HRTEM images of the obtained NiO.

Fig. 6. (a) XRD pattern and (b) EDS spectrum of the obtained NiO.

Fig. 7. (a) Low, (b) high magnification FESEM images, and (c) XRD of the $\mathrm{NiO} /$ graphene nanocomposite.

Fig. 8. Magnetization versus applied magnetic field at room temperature for (a) pure NiO nanostructures and (b) $\mathrm{NiO} /$ graphene nanocomposite.

Fig. 9. UV-vis spectra of (a) pure $\mathrm{NiO}$ nanoparticles, (b) $\mathrm{NiO} /$ graphene nanocomposite and (c) pure graphene, (d) curve (Ahv) ${ }^{\mathrm{n}}$ versus hv of the $\mathrm{NiO} /$ graphene nanocomposite.

Fig. 10. Degradation of MO in presence of NiO/graphene nanocomposite and pure NiO nanoparticles under UV irradiation.

Fig. 11. Degradation of $\mathrm{MO}$ in presence of $\mathrm{NiO} /$ graphene nanocomposite and pure NiO nanoparticles under visible light irradiation. 


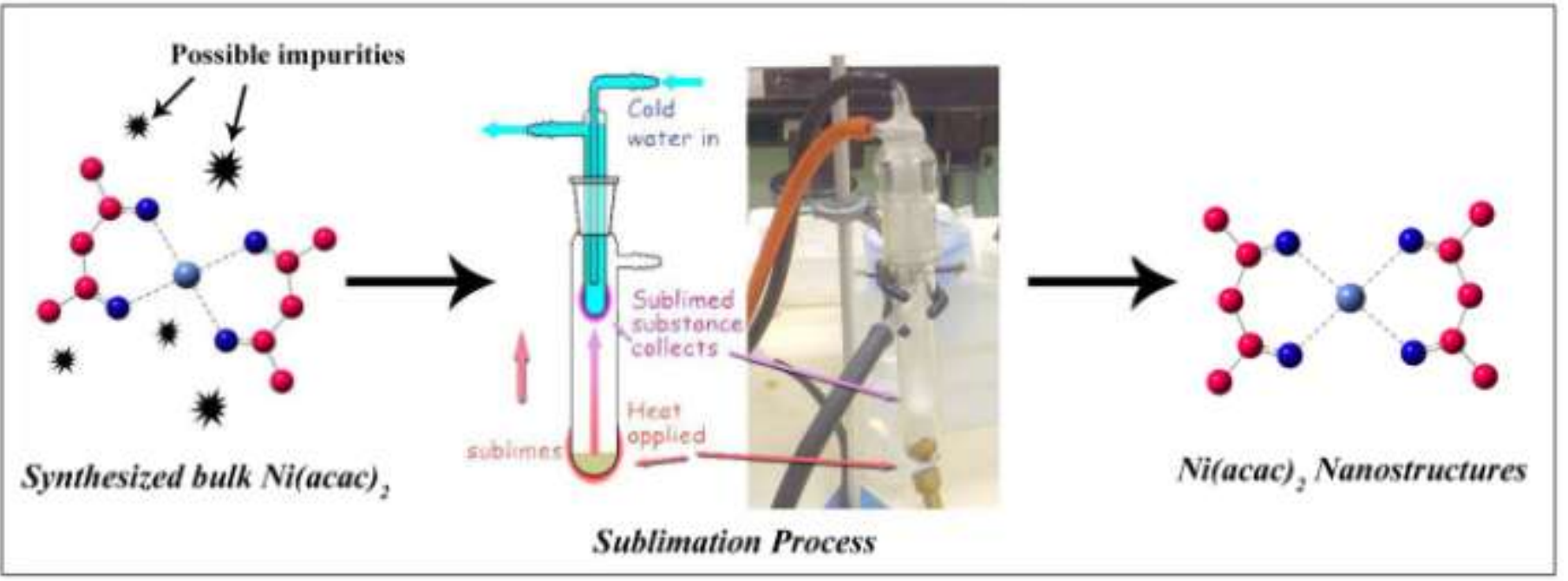

Fig. 1. 


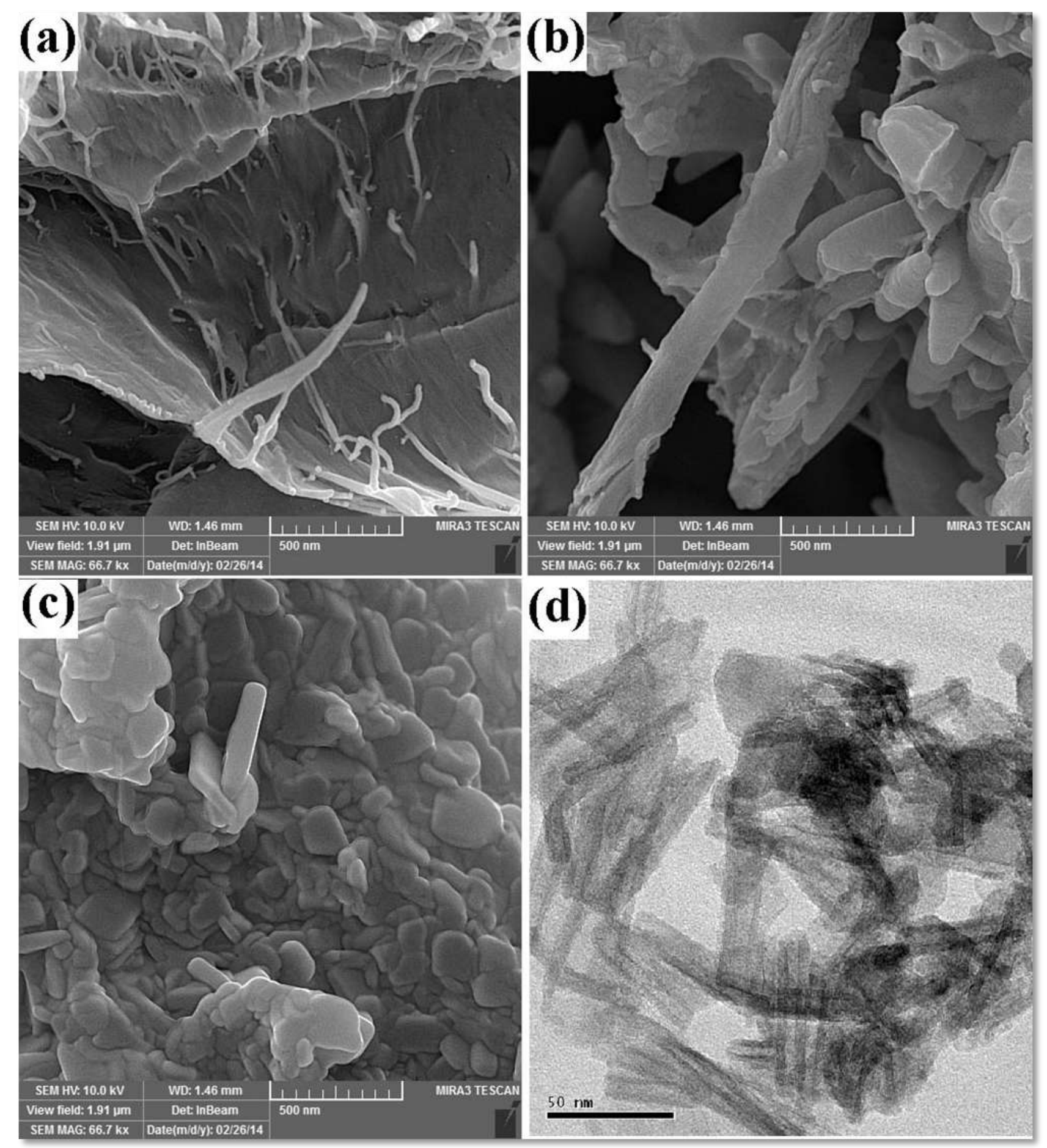

Fig. 2. 


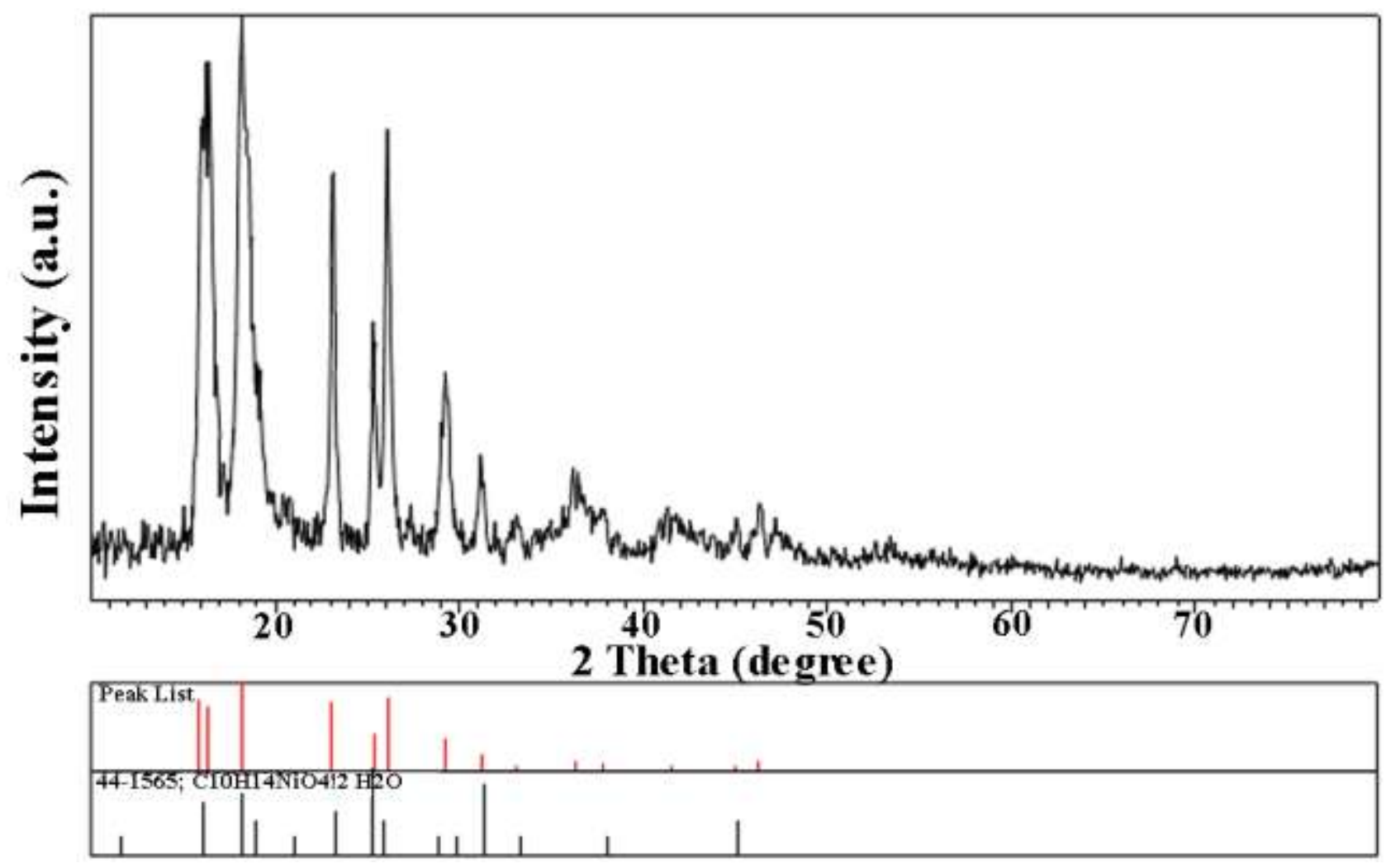

Fig. 3. 

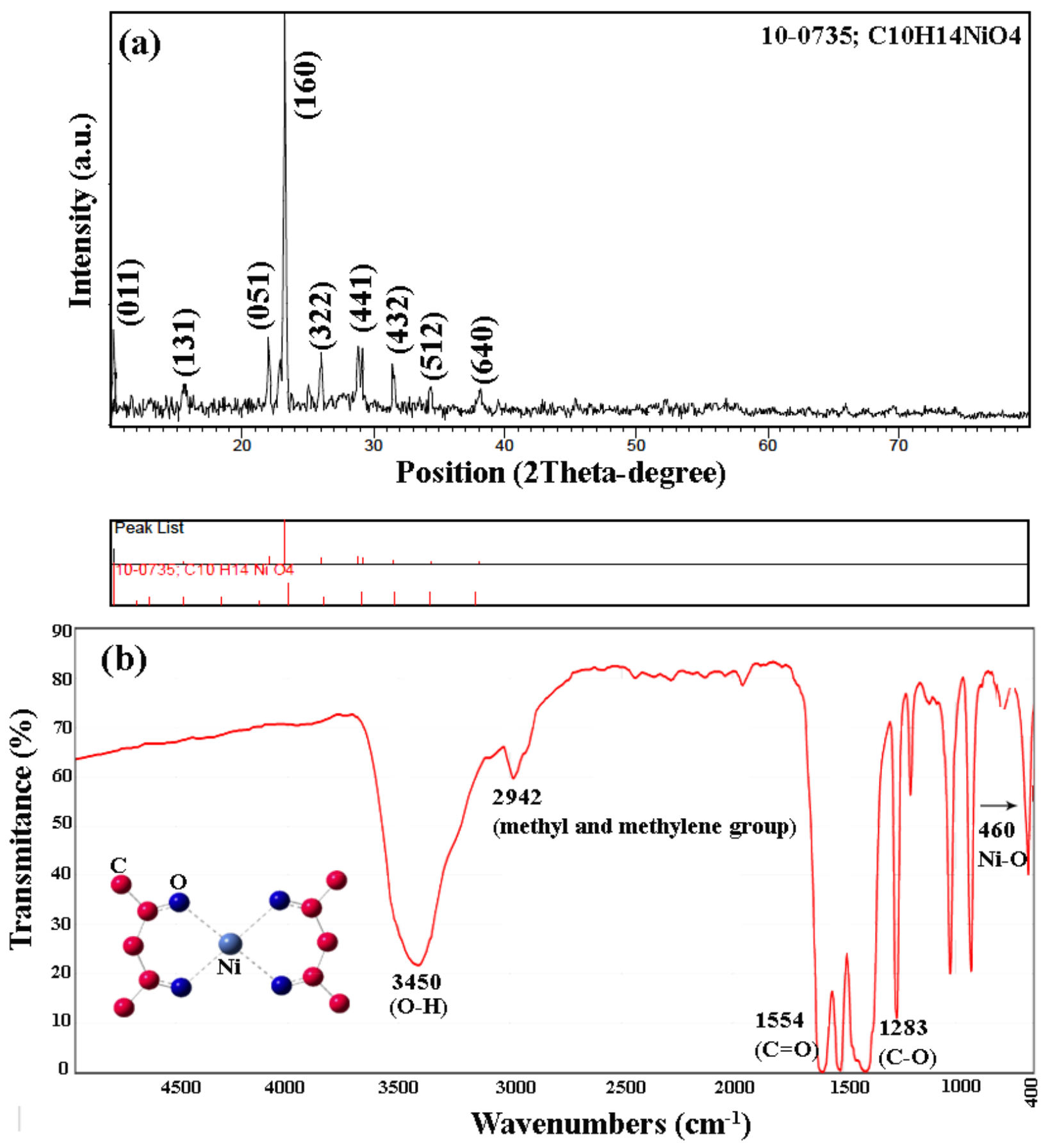

Fig. 4. 


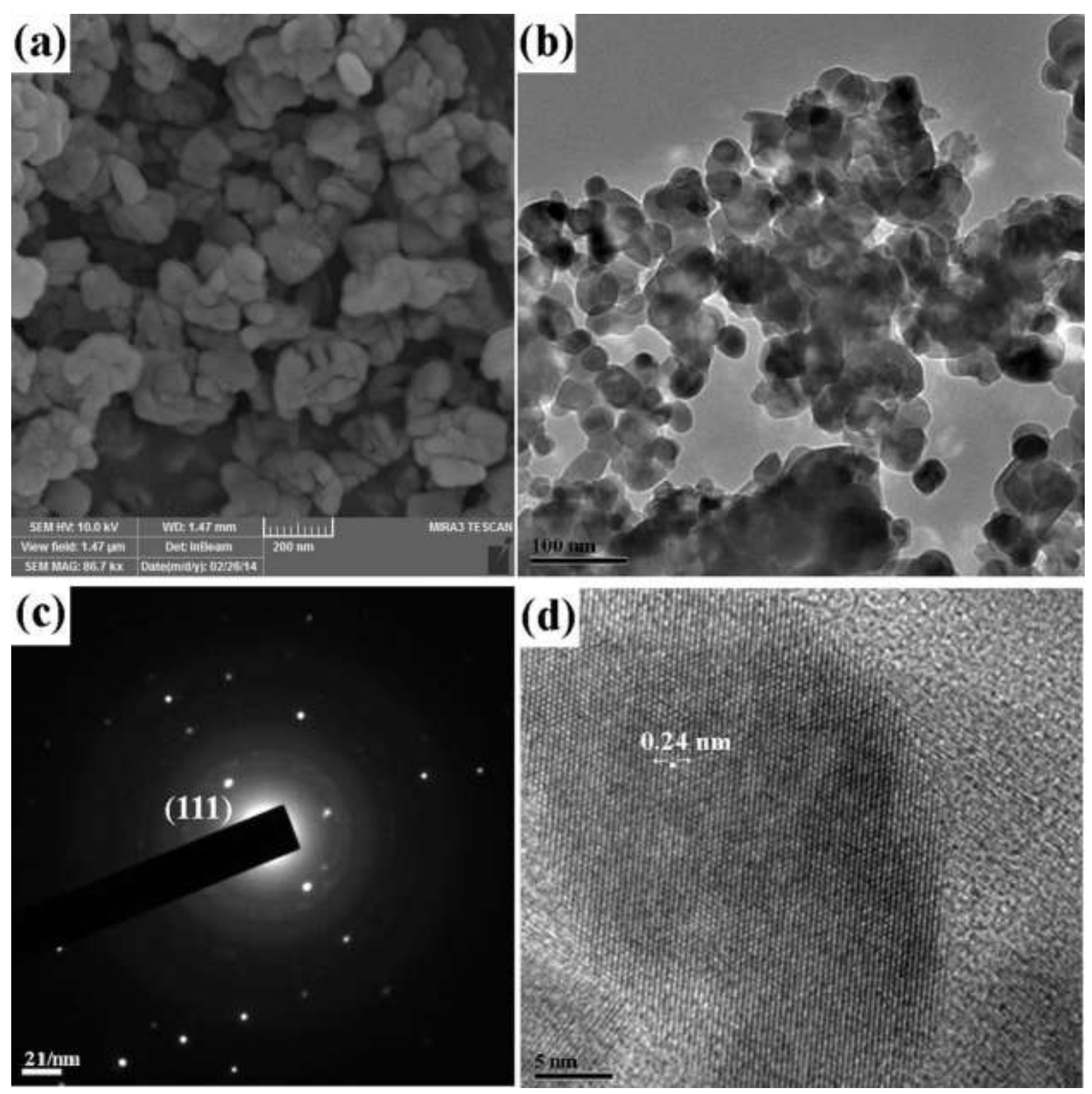

Fig. 5. 

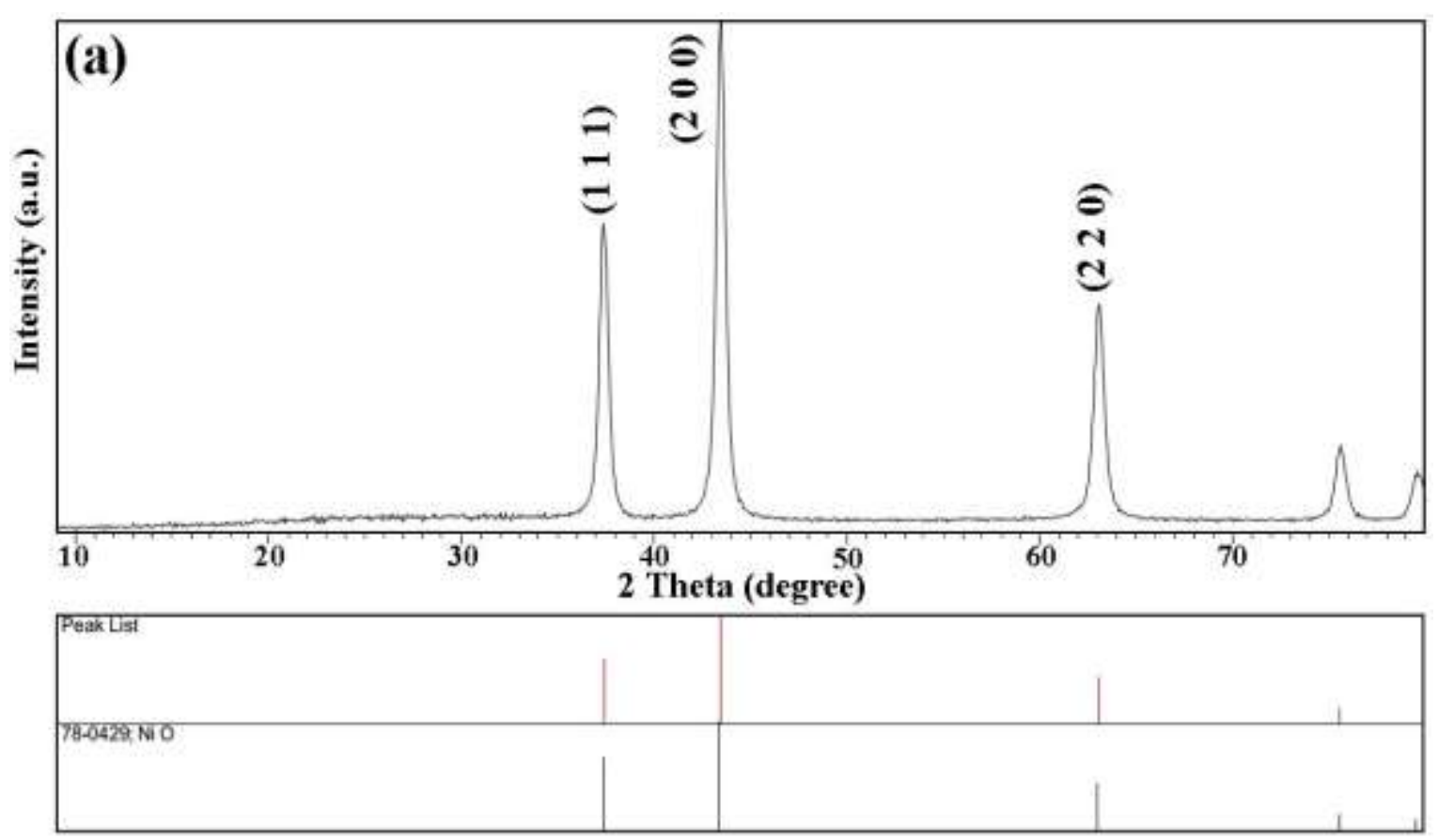

(b)

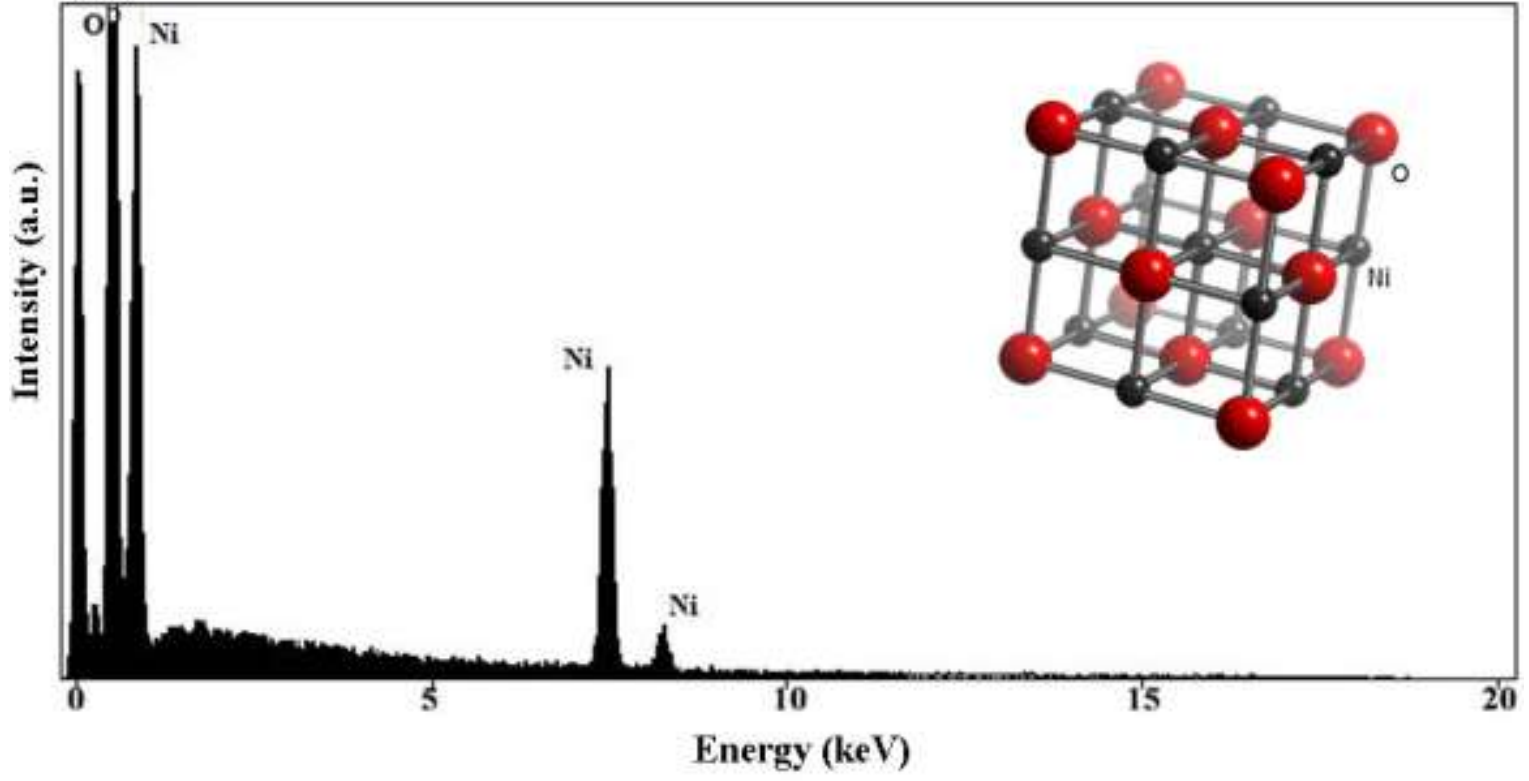

Fig. 6. 


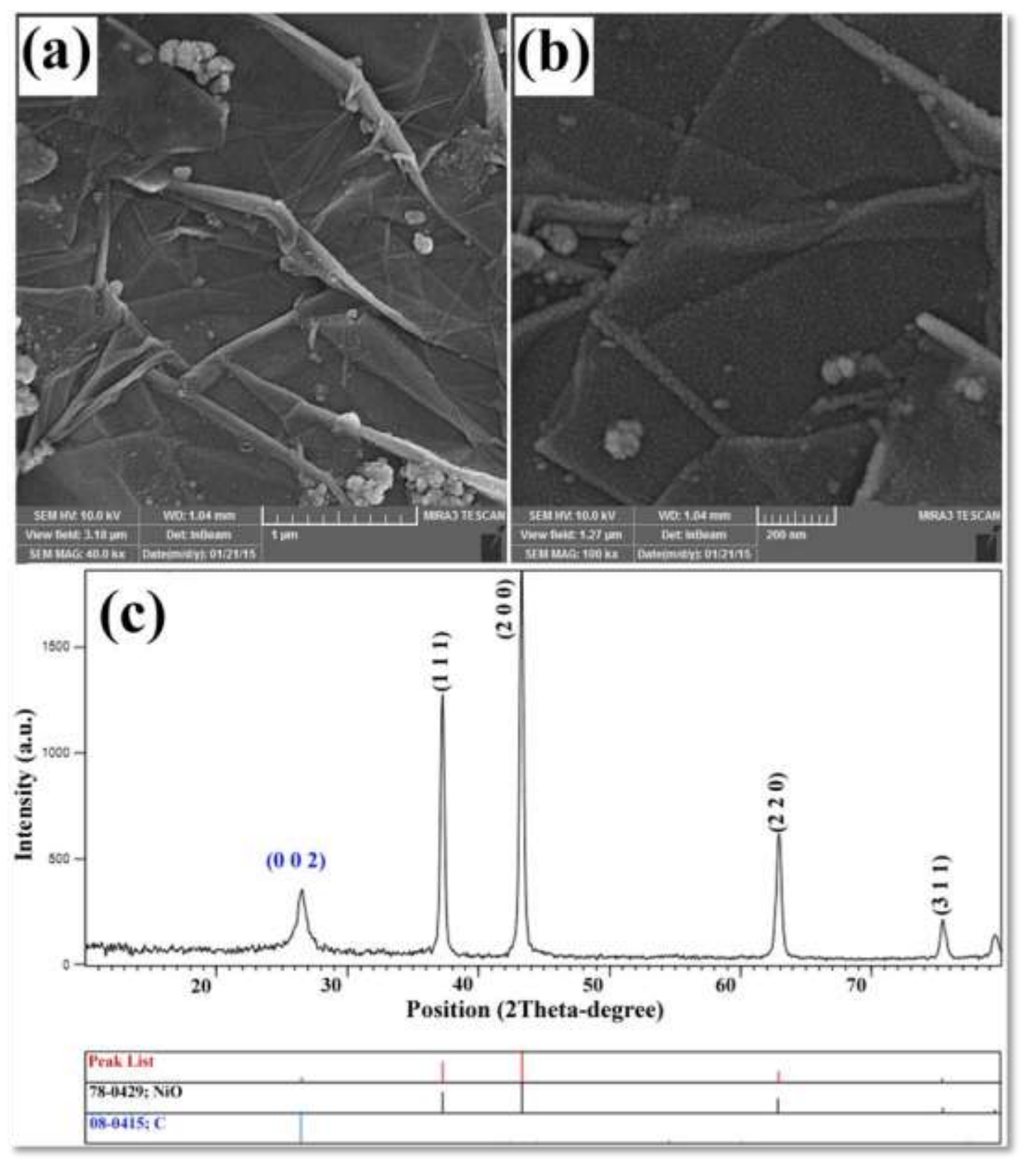

Fig. 7. 

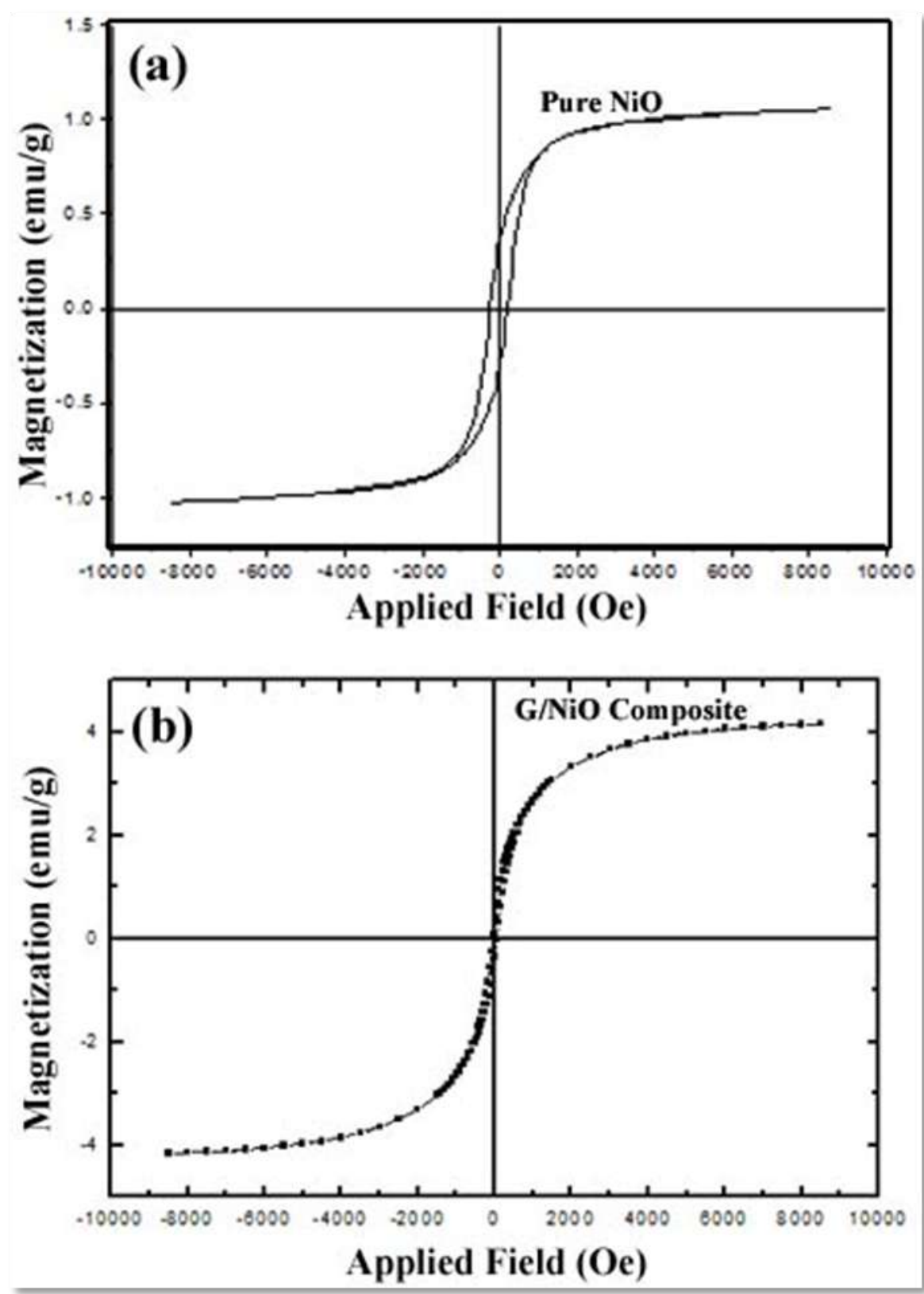

Fig. 8. 

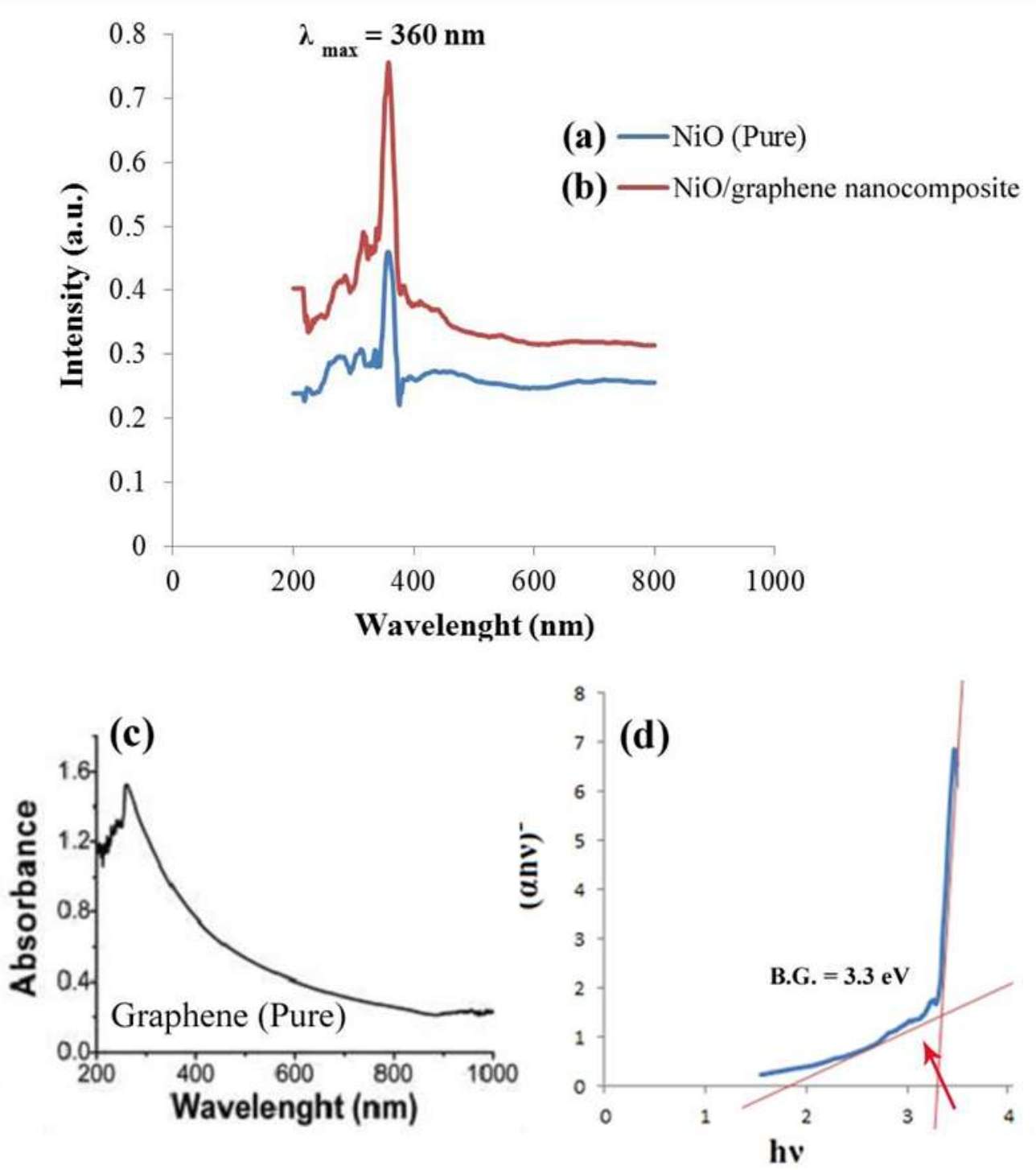

Fig. 9. 


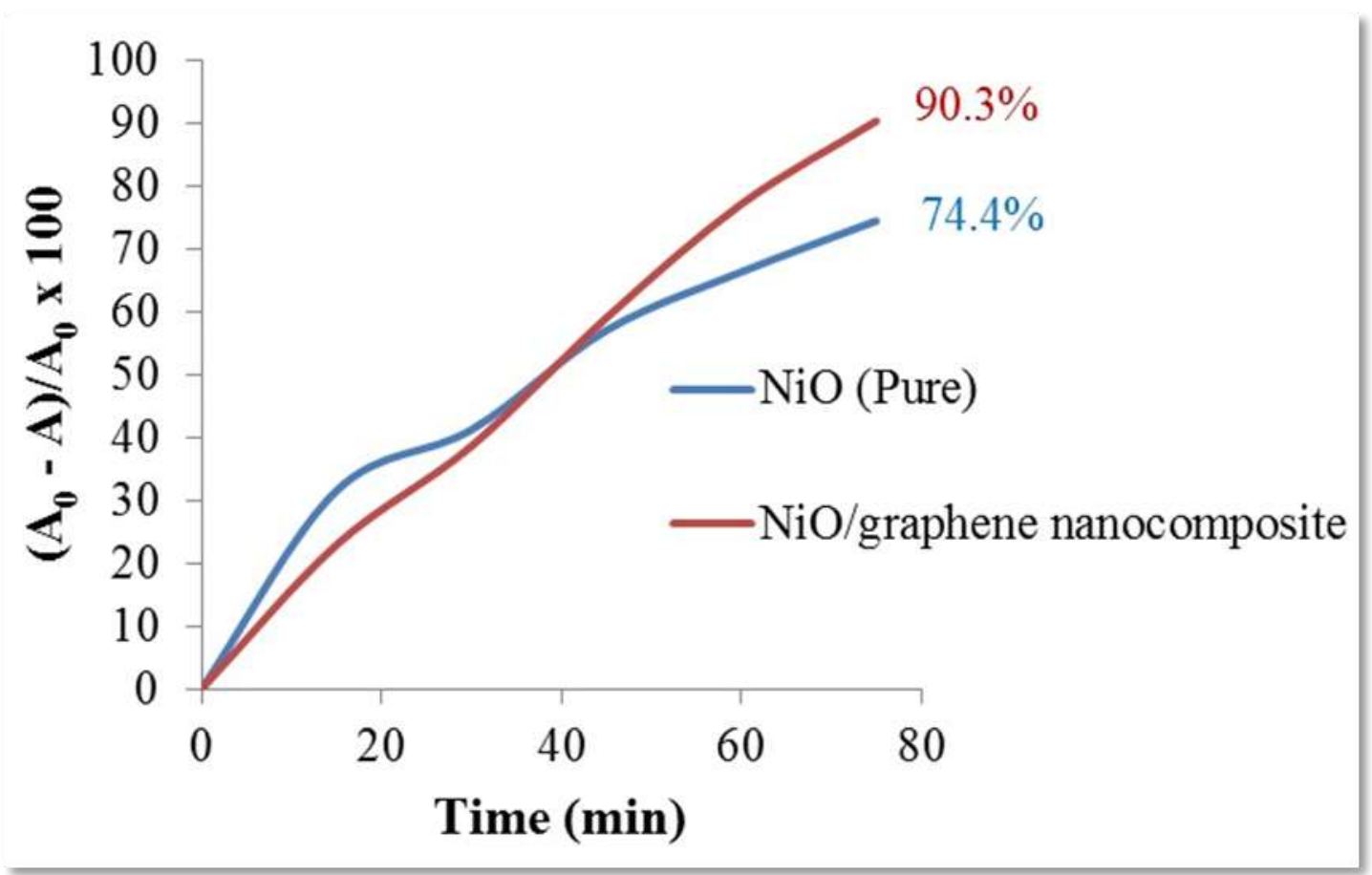

Fig. 10. 


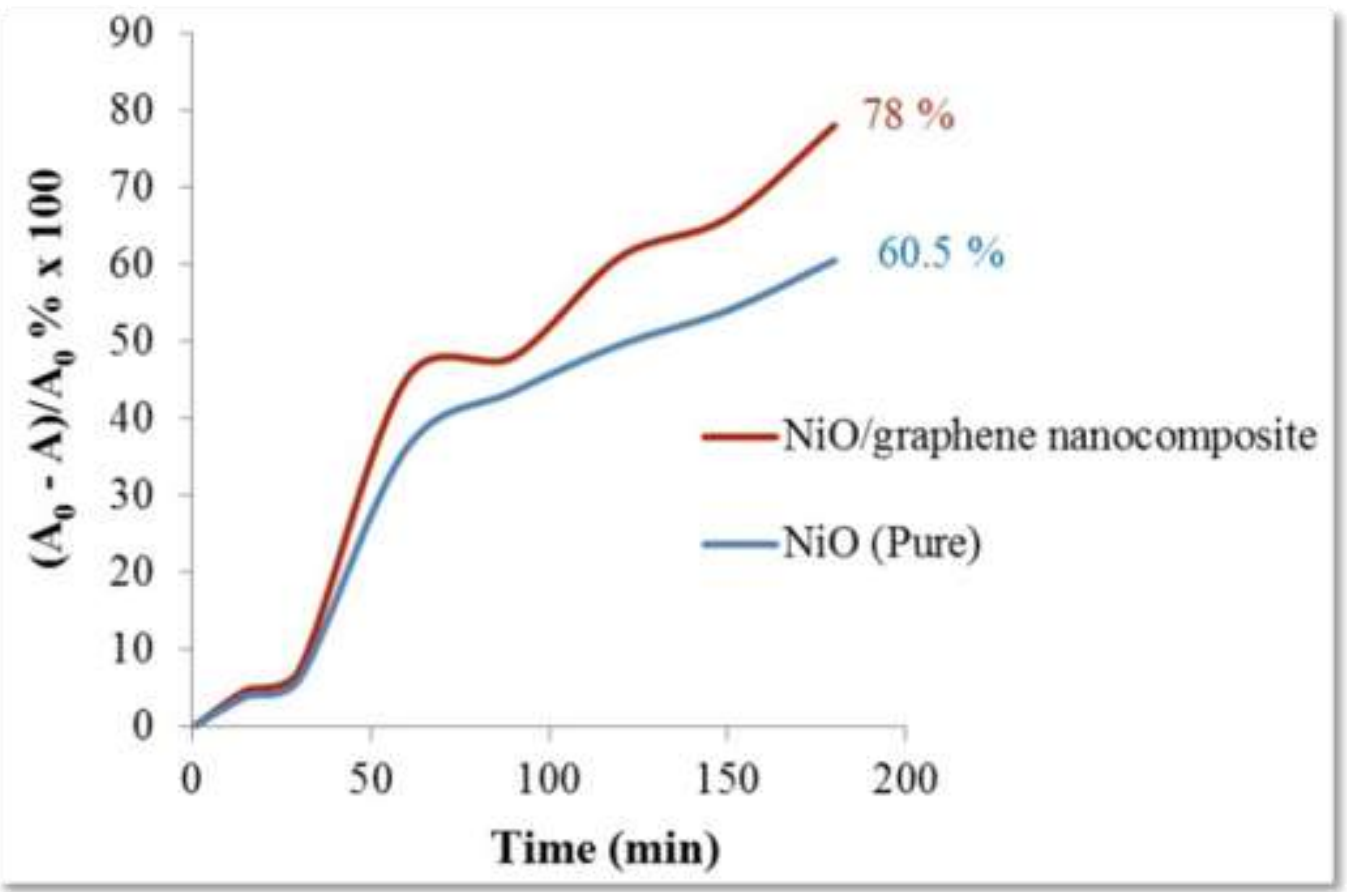

Fig. 11. 